\title{
Hubungan Antara Persepsi terhadap Layanan Bimbingan Belajar dengan Kemandirian Belajar Peserta Didik Sekolah Menengah Pertama
}

\author{
Andika Ari Saputra, Budi Astuti \\ Program Studi Bimbingan dan Konseling, Program Pascasarjana, Universitas Negeri Yogyakarta, \\ Jl. Colombo No.1, Sleman, Daerah Istimewa Yogyakarta, Indonesia 55281 \\ Email: ari.andika75@yahoo.com
}

Artikel diterima: 8 September 2017; direvisi 6 November 2017; disetujui 27 Maret 2018

\begin{abstract}
This study is intended to identify the correlation between perception on tutoring services and Junior High School students' autonomy. This study was a correlational and expose facto study. The population of this study is the entire students of Sekolah Menengah Pertama Negeri 10 Yogyakarta amount to 506 students. Then, this study took 253 students as research sample which is determined by using proportional stratified random sampling. The data were obtained employing perception on tutoring services scale and students' autonomy scale. Cronbach's Alpha was used to examine the reliability and it obtained $p=0,743$ for perception on tutoring services and $p=0,744$ students' autonomy. To analyze the data, we employes statistical analysis. The results confirm that between perception on tutoring services and students' autonomy of Sekolah Menengah Pertama Negeri 10 Yogyakarta are positively correlated.
\end{abstract}

Keywords: perceptions; tutoring services; learner autonomy; junior high school

\begin{abstract}
Abstrak: Penelitian ini bertujuan untuk mengetahui hubungan antara persepsi terhadap layanan bimbingan belajar dengan kemandirian belajar peserta didik Sekolah Menengah Pertama (SMP). Penelitian ini merupakan penelitian korelasi dan expose facto. Populasi penelitian ini adalah seluruh peserta SMP Negeri 10 Yogyakarta yang berjumlah 507 orang. Sampel sejumlah 253 peserta didik ditentukan dengan teknik proportional stratified random sampling. Metode pengumpulan data menggunakan skala persepsi terhadap layanan bimbingan belajar dan skala kemandirian belajar. Uji validitas instrumen menggunakan koefisien korelasi product moment. Uji reliabilitas dengan menggunakan teknik Alpha Cronbach, diperoleh $\mathrm{p}=0,743$ untuk variabel persepsi terhadap layanan bimbingan belajar, dan $\mathrm{p}=0,744$ untuk variabel kemandirian belajar. Teknik analisis menggunakan analisis statistik. Hasil penelitian menunjukkan bahwa ada hubungan positif antara persepsi terhadap layanan bimbingan belajar dengan kemandirian belajar peserta didik SMP Negeri 10 Yogyakarta.
\end{abstract}

Kata kunci: persepsi; layanan bimbingan belajar; kemandirian belajar; SMP

Peserta didik SMP membutuhkan layanan bimbingan dan konseling (BK), terutama pada bidang layanan bimbingan pribadi, sosial, belajar dan karier. Layanan BK dapat membantu peserta didik untuk memperoleh kesejahteraan lahir dan batin dalam proses pendidikan yang ditempuhnya, sehingga mencapai tujuan pendidikan. Seperti halnya layanan bimbingan belajar yang dapat membantu peserta didik dalam proses belajar agar peserta didik merasa nyaman dalam suasana belajar yang kondusif untuk mencapai pertumbuhan dan perkembangan yang optimal. Untuk dapat memberikan bantuan yang tepat dan efektif, Guru BK perlu melakukan assessment (Nyutu \& Gysbers, 2008). 
Peserta didik pada usia remaja adalah anak muda yang berjuang untuk mencari tahu siapa dirinya (Feist \& Feist, 2002). Pada tahap perkembangan ini, peserta didik menarik diri dari beragam gambaran diri sebelumnya yang telah diterima dan ditolak. Ketika remaja, bibit identitas yang bertunas selama masa bayi dan terus tumbuh hingga remaja ini dikuatkan dalam krisis yang peserta didik coba atasi dengan konflik psikososial identitas versus kebingungan identitas. Guru BK dan orang tua sebaiknya melakukan pengamatan terhadap perkembangan anak di lingkungan sekolah maupun masyarakat, guna membantu peserta didik dalam menemukan identitas diri serta dapat bersosial dengan lingkungan belajarnya.

Selanjutnya, dari konflik industri versus rendah diri, anak usia sekolah mengembangkan kekuatan dasar kompetensi, yaitu rasa percaya diri untuk menggunakan kemampuan fisik dan kognitif dalam menyelesaikan masalah dalam usia sekolah (Erikson, 1994). Apabila pertentangan antara industri dan rasa rendah diri tidak condong ke rasa rendah diri atau industri, anak usia remaja akan terpaku dengan khayalan genital dan mereka akan menghabiskan sebagian besar waktunya untuk hal yang tidak produktif.

Sekolah adalah salah satu wadah pembelajaran pendidikan formal untuk melaksanakan proses pembelajaran secara optimal dalam mengembangkan kompetensi yang dimiliki peserta didik. BK sebagai salah satu komponen penyelenggaraaan pendidikan di sekolah, berperan membantu peserta didik untuk mengembangkan kemampuan fisik dan kognitif dalam menyelesaikan masalah belajar sehingga peserta didik memiliki kemampuan yang baik untuk mandiri dalam belajar.

Kemandirian dalam belajar merupakan upaya peserta didik untuk sukses dalam mempersiapkan segala kebutuhan belajar, memulai belajar dan mengatur waktu dalam belajar (Fitriana, Ihsan, \& Annas, 2015). Peserta didik yang mandiri dalam belajar dapat mengetahui kekurangan diri dalam belajar dan dapat mengevaluasi hasil belajarnya sehingga mampu berkembang secara optimal dan berhasil dalam studinya. Di lingkungan sekolah, masih terlihat bahwa ada beberapa peserta didik yang kurang mandiri. Mereka belum percaya diri dalam mengerjakan tugas. Peserta didik tersebut masih menyandarkan diri pada orang lain, dan memiliki rasa tanggung jawab dalam mengerjakan tugas yang rendah (Sunarsih, 2010). Hal ini menegaskan bahwa kemandirian belajar peserta didik juga dipengaruhi oleh layanan bimbingan belajar yang dapat memengaruhi prestasi belajar. Pemberian layanan bimbingan belajar juga sangat membantu peserta didik menemukan cara belajar yang efektif.

Layanan bimbingan belajar adalah bimbingan dalam hal menemukan cara belajar yang tepat, dapat memilih program studi yang sesuai, dan dalam mengatasi kesukaran yang timbul terkait dengan tuntutan-tuntutan belajar di suatu institusi pendidikan (Winkel \& Hastuti, 2005). Pemberian layanan bimbingan belajar dipengaruhi oleh persepsi peserta didik yang menganggap layanan bimbingan belajar penting dan bermanfaat (Zhan, Bray, Wang, Lykins, \& Kwo, 2013). Apabila peserta didik mempersepsikan layanan bimbingan belajar dengan baik, maka peserta didik dapat menginterprestasikan dan memberikan reaksi menerima kehadiran layanan bimbingan belajar.

Pada dasarnya peserta didik diajak untuk terampil merencanakan pendidikan, memiliki kesiapan menghadapi ujian, memiliki kebiasaan belajar teratur dan mencapai hasil belajar secara optimal sehingga dapat mencapai kesuksesan, kesejahteraan, dan kebahagiaan dalam hidupnya (Peraturan Menteri Pendidikan dan Kebudayaan Republik Indonesia, 2015; Prasetya, Winarno, \& Eriany, 2013). Beberapa permasalahan yang dialami peserta didik terkait dengan kebiasaan belajar yaitu belum memiliki persepsi positif layanan bimbingan belajar. Hal ini dapat membuat peserta didik tidak menemukan cara belajar yang tepat.

Keberadaan BK yang sangat terasa dibutuhkan di sekolah (Brouzos, Vassilopoulos, Korfiati, \& Baourda, 2015), belum mampu membuat seluruh siswa belajar dengan mandiri. Studi awal di lapangan pada Juli 2016 menunjukkan bahwa Guru BK SMP Negeri 10 Yogyakarta telah memberikan layanan secara maksimal, namun masih ada sebagian peserta didik belum mandiri dalam belajar. Peserta didik yang belum memiliki kemandirian belajar, terlihat tidak percaya diri dalam mengerjakan tugas dan belum memandang positif layanan bimbingan belajar. 
Program layanan bimbingan belajar dapat meningkatkan kemandirian belajar dan dapat memperbaiki kondisi belajar peserta didik (Sriyono, 2016). Terkait dengan hal tersebut, kami membatasi permasalahan yang berkaitan dengan kemandirian belajar peserta didik. Berdasarkan uraian latar belakang masalah yang sudah ditulis, kami ingin mengetahui apakah ada hubungan antara persepsi terhadap layanan bimbingan belajar dengan kemandirian belajar peserta didik SMP Negeri 10 Yogyakarta. Hasil penelitian diharapkan dapat memberikan masukan dalam perkembangan ilmu pengetahuan, terutama dalam bidang BK, serta dapat memberikan kontribusi dalam upaya memperluas cakrawala pengetahuan dalam pemberian layanan bimbingan belajar dan kemandirian belajar pada peserta didik.

\section{METODE}

Penelitian ini adalah jenis penelitian korelasi dan expose facto. Desain korelasi memberikan kesempatan bagi peneliti untuk melihat skor dan menjelaskan hubungan antar variabel. Peneliti menggunakan uji statistik untuk menggambarkan dan mengukur derajat asosiasi (atau hubungan) antara dua atau lebih variabel (Creswell, 2002). Populasi penelitian ini adalah seluruh peserta didik SMP Negeri 10 Yogyakarta yang berjumlah 507 orang. Sampel sejumlah 253 peserta didik ditentukan dengan teknik proportional stratified random sampling. Penelitian dilakukan pada April-Mei 2017.

Metode pengumpulan data menggunakan skala persepsi terhadap layanan bimbingan belajar dan skala kemandirian belajar dilakukan dengan menyebarkan skala kepada sampel. Skala diedarkan dengan tujuan untuk memperoleh data tentang identitas sampel, karakteristik sampel dan data variabel penelitian yaitu persepsi peserta didik terhadap layanan bimbingan belajar dengan kemandirian belajar. Instrumen atau alat yang digunakan dalam penelitian ini berupa butir pernyataan persepsi terhadap layanan bimbingan belajar, dan butir pernyataan kemandirian belajar. Instrumen penelitian disusun menggunakan empat alternatif jawaban yaitu: sangat sesuai (SS); sesuai (S); tidak sesuai (TS); dan sangat tidak sesuai (STS) (Azwar, 2013).

Uji validitas menggunakan pendapat dari ahli (expert judgement) yaitu uji validitas konstruk. Uji reliabilitas dengan menggunakan teknik Alpha Cronbach, yang diperoleh nilai $p=0,743$ untuk variabel persepsi terhadap layanan bimbingan belajar dan nilai $p=0,744$ untuk variabel kemandirian belajar. Teknik yang digunakan adalah analisis statistik. Langkah-langkah yang ditempuh dalam analisis data berikutnya adalah uji persyaratan pengujian hipotesis. Uji ini terdiri dari dua macam uji persyaratan yaitu uji normalitas dan uji linieritas. Agar persamaan garis regresinya dapat ditentukan perlu diketahui dulu harga koefisien korelasi prediktor (a) dan bilangan konstannya (k), selanjutnya garis regresi diuji taraf signifikannya (5\%).

\section{HASIL}

\section{Deskripsi Data Variabel Persepsi Terhadap Layanan Bimbingan Belajar}

Data yang diperoleh dari 253 peserta didik dan 40 butir pernyataan yang dinyatakan sahih dengan program SPSS 22 for Windows dapat dideskripsikan sebagai berikut : skor tertinggi $=159$; skor terendah $=102 ;$ mean $=134,32 ;$ median $=137,00 ;$ mode $=131 ;$ dan simpangan baku $=13,029$. Untuk mengetahui kecenderungan rata-rata skor variabel persepsi terhadap layanan bimbingan belajar peserta didik SMP Negeri 10 Yogyakarta tahun pelajaran 2016/2017 dibedakan menjadi empat kategori yang memiliki rentang skor minimal ideal 40 sampai dengan skor maksimal ideal 160. Rentang skor ideal adalah skor tertinggi dikurangi skor terendah, yaitu $160-40=120$, dan panjang interval skor ideal dibagi dengan empat, yaitu $120: 4=30$. Selanjutnya dapat dibuat perhitungan mulai skor terendah sebagai berikut : (1) skor 40-70= sangat negatif, (2) skor $71-100$ = negatif, (3) skor 101-130 = positif, (4) skor 131-160 = sangat positif.

Berdasar pada pedoman konversi di atas, rerata hasil penelitian diperoleh angka sebesar 134,32 yang terletak pada interval 131-160. Hal ini berarti tingkat persepsi terhadap layanan bimbingan belajar peserta didik SMP Negeri 10 Yogyakarta tahun pelajaran 2016/2017 tergolong sangat positif. 
Distribusi frekuensi perolehan skor variabel persepsi terhadap layanan bimbingan belajar yang ditentukan dalam delapan kelas interval disajikan pada tabel 1, sedangkan frekuensi skor variabel persepsi terhadap layanan bimbingan belajar disajikan pada tabel 2

\section{Deskripsi Data Variabel Kemandirian Belajar}

Data yang diperoleh dari 253 peserta didik dan 44 butir pernyataan yang dinyatakan sahih dengan komputer program SPSS 22 for Windows dapat dideskripsikan sebagai berikut : skor tertinggi $=174$; skor terendah $=115 ;$ mean $=147,63 ;$ median $=148,00 ;$ mode $=152 ;$ dan simpangan baku $=13,941$. Untuk mengetahui kecenderungan rata-rata skor variabel kemandirian belajar peserta didik SMP Negeri 10 Yogyakarta tahun pelajaran 2016/2017 dibedakan 4 kategori yang memiliki rentang skor minimal ideal 44 sampai dengan skor maksimal ideal 176. Rentang skor ideal adalah skor tertinggi dikurangi skor terendah, yaitu $176-44=132$, dan panjang interval skor ideal dibagi dengan 4 , yaitu $132: 4=33$. Selanjutnya dapat dibuat perhitungan mulai skor terendah sebagai berikut : (1) skor 4477 = rendah, (2) skor 78-110 = sedang, (3) skor 111-143 = tinggi, (4) skor 144-176 = sangat tinggi

Berdasar pada pedoman konversi di atas, rerata hasil penelitian diperoleh angka sebesar 147,63 terletak pada interval 144-176 yang berarti tingkat manajemen diri peserta didik SMP Negeri 10 Yogyakarta tergolong sangat tinggi. Selanjutnya distribusi frekuensi perolehan skor variabel kemandirian belajar disajikan pada tabel 3, dan frekuensi skor variabel kemandirian belajar disajikan pada tabel 4 .

\section{Pengujian Prasyarat Analisis}

Sehubungan dengan teknik analisis data yang menggunakan analisis korelasi sampai analisis regresi, maka terlebih dahulu dilakukan pengujian prasyarat analisis regresi mendasarkan atas sejumlah asumsi, diantaranya yaitu bahwa variabel terikat $Y$ mengikuti sebaran normal dan korelasi antara $\mathrm{X}$ dengan $\mathrm{Y}$ adalah linier.

\section{Uji Normalitas Sebaran}

Uji normalitas sebaran dilaksanakan dengan bantuan komputer dan didapat nilai chi kuadrat $(\chi 2)$ untuk variabel persepsi terhadap layanan bimbingan belajar. Kaidah yang digunakan untuk uji normalitas sebaran adalah : "Jika $p>0,05$ maka sebarannya dinyatakan normal, dan sebaliknya jika $\mathrm{p} \leq 0,05$ sebarannya dinyatakan tidak normal". Uji normalitas menggunakan Kolmogorov-Smirnov Lilliefors. Jika sig $<\alpha$ berarti tidak berdistribusi normal, selanjutnya jika sig $>\alpha$ berarti berdistribusi normal, digunakan tingkat kepercayaan 95\%, dengan tingkat signifikansi $(\alpha)=100 \%$ - tingkat kepercayaan $=100 \%-95 \%=5 \%=0,05$.

Berdasarkan hasil perhitungan yang dilakukan dengan bantuan komputer program SPSS 22 for Windows, variabel persepsi terhadap layanan bimbingan belajar diperoleh Sig $>\alpha(0,071>$ $0,05)$ berarti variabel persepsi terhadap layanan bimbingan belajar berdistribusi normal. Variabel kemandirian belajar diperoleh $\mathrm{Sig}>\alpha(0,060>0,05)$ berarti variabel kemandirian belajar berdistribusi normal.

\section{Uji Linieritas Hubungan}

Uji linieritas dilakukan untuk mengetahui linier atau tidaknya hubungan tiap prediktor terhadap kriterium. Kaidah yang digunakan untuk uji linieritas adalah sebagai berikut: uji linieritas menggunakan Deviation from linearity, jika sig $<\alpha$ berarti tidak linier, jika sig $>\alpha$ berarti linier. Digunakan tingkat kepercayaan 95\%, tingkat signifikansi $(\alpha)=100 \%$ - tingkat kepercayaan $=100 \%$ $-95 \%=5 \%=0,05$

Setelah dilakukan uji linieritas dengan bantuan komputer SPSS 22 for Windows, hasil menunjukkan linieritas hubungan antara variabel persepsi terhadap layanan bimbingan belajar dengan kemandirian belajar diperoleh $\mathrm{Sig}>\alpha(0,163>0,05)$. Hal tersebut berarti Sig $>\alpha$ sehingga bentuk hubungan adalah linier. 
Tabel 1 Distribusi Frekuensi Skor Variabel Persepsi Terhadap Layanan Bimbingan Belajar

\begin{tabular}{ccccc}
\hline No & $\begin{array}{c}\text { Kelas } \\
\text { Interval }\end{array}$ & Frekuensi & Persen (\%) & $\begin{array}{c}\text { Persen } \\
\text { Kumulatif (\%) }\end{array}$ \\
\hline 1 & $102-109$ & 9 & 3,5 & 3,5 \\
2 & $110-117$ & 16 & 6,3 & 9,8 \\
3 & $118-125$ & 33 & 13 & 22,8 \\
4 & $126-133$ & 56 & 22,1 & 44,9 \\
5 & $134-141$ & 58 & 23 & 67,9 \\
6 & $142-149$ & 55 & 22 & 89,9 \\
7 & $150-157$ & 18 & 7,1 & 97 \\
8 & $158-165$ & 8 & 3,2 & 100 \\
& Jumlah & 253 & 100 & 100 \\
\hline
\end{tabular}

Tabel 2 Frekuensi Skor Variabel Persepsi Terhadap Layanan Bimbingan Belajar

\begin{tabular}{cccc}
\hline Skor & Kategori & Frekuensi & Persen (\%) \\
\hline $40-70$ & Negatif & 0 & 0 \\
$71-100$ & Sangat Negatif & 0 & 0 \\
$101-130$ & Positif & 96 & 37,94 \\
$131-160$ & Sangat Positif & 157 & 62,06 \\
Jumlah & 253 & 100 \\
\hline
\end{tabular}

Tabel 3 Distribusi Frekuensi Skor Variabel Kemandirian Belajar

\begin{tabular}{ccccc}
\hline No & $\begin{array}{c}\text { Kelas } \\
\text { Interval }\end{array}$ & Frekuensi & Persen (\%) & $\begin{array}{c}\text { Persen } \\
\text { Kumulatif (\%) }\end{array}$ \\
\hline 1 & $115-122$ & 15 & 6 & 6 \\
2 & $123-130$ & 18 & 7,1 & 13,1 \\
3 & $131-138$ & 22 & 8,7 & 21,8 \\
4 & $139-146$ & 53 & 21 & 42,8 \\
5 & $147-154$ & 68 & 26,7 & 69,5 \\
6 & $155-162$ & 42 & 16,6 & 86,1 \\
7 & $163-170$ & 27 & 10,7 & 96,8 \\
8 & $171-178$ & 8 & 3,2 & 100 \\
& Jumlah & 253 & 100 & 100 \\
\hline
\end{tabular}

Tabel 4 Frekuensi Skor Variabel Kemandirian Belajar

\begin{tabular}{cccc}
\hline Skor & Kategori & Frekuensi & Persen (\%) \\
\hline $44-77$ & Rendah & 0 & 0 \\
$78-110$ & Sedang & 0 & 0 \\
$111-143$ & Tinggi & 7 & 38,33 \\
$144-176$ & Sangat Tinggi & 156 & 61,70 \\
Jumlah & 253 & 100 \\
\hline
\end{tabular}

\section{PEMBAHASAN}

Hasil penelitian menunjukkan bahwa ada hubungan antara persepsi terhadap layanan bimbingan belajar dengan kemandirian belajar peserta didik SMP Negeri 10 Yogyakarta tahun pelajaran 2016/2017. Semakin positif persepsi peserta didik terhadap layanan bimbingan belajar, maka akan semakin tinggi kemandirian peserta didik. Pemberian layanan bimbingan belajar yang membantu peserta didik untuk menumbuhkan dan mengamalkan sikap serta kebiasaan belajar yang baik dalam menguasai pengetahuan dan keterampilan sejalan dengan perkembangan ilmu pengetahuan, 
teknologi dan kesenian serta mempersiapkan peserta didik untuk melanjutkan pendidikan ke tingkat yang lebih tinggi atau untuk terjun ke lapangan pekerjaan bidang tertentu (Amin, 2010). Layanan bimbingan belajar yang dapat membangun lingkungan belajar kondusif (Çakiroğlu \& Öngöz, 2017), bahkan mengurangi resiko drop-out (Da Re, Clerici, \& Álvarez Pérez, 2017) perlu persiapan dan kerangka program yang matang, hal ini agar bimbingan belajar yang diberikan efektif (Holland, Grant, \& Donthamsetty, 2018).

Pelaksanaan BK oleh konselor profesional akan mampu mengarahkan peserta didik untuk memiliki cara belajar yang efektif (Modo, Sanni, \& Mogbo, 2013). Lewat layanan bimbingan belajar, peserta didik mampu mengatasi tantangan dalam belajar dan memecahkan masalah dalam belajar sesuai dengan kemampuan diri, minat serta bakatnya. Layanan bimbingan belajar juga dapat meningkatkan kemandirian belajar dan dapat memperbaiki kondisi belajar peserta didik (Sriyono, 2016). Sejalan dengan hasil penelitian tersebut, hasil penelitian lain menyebutkan bahwa layanan bimbingan dan konseling berpengaruh terhadap hasil belajar peserta didik (Dabone, Graham, \& Fabea, 2015). Layanan bimbingan dan konseling membantu peserta didik dalam memahami diri dalam belajar (Prasertsung, Chano, \& Boonleang Thumthong, 2012) dan terampil memecahkan kesulitan dalam belajar serta mampu menerapkan cara belajar yang efektif (Modo et al., 2013). Layanan bimbingan belajar kepada peserta didik yang efektif, juga akan membantu mereka mengembangkan segenap potensi yang dimiliki dalam belajar agar mampu mendapatkan hasil belajar yang baik.

Kemandirian peserta didik yang secara tidak langsung berasosiasi positif dengan well-being (Levesque, Zuehlke, Stanek, \& Ryan, 2004), dapat ditingkatkan dengan beberapa kegiatan. Beberapa kegiatan yang dapat meningkatkan kemandirian peserta didik antara lain: mendengarkan; mengerjakan tugas mandiri; berbicara di dalam kelas; mendapat pujian atas keberhasilan; mendapat respon atas pertanyaan dan komentar; dan mendapat penghargaan atas pendapat dan pengalamannya (Reeve \& Jang, 2006). Kemandirian peserta didik yang harus terus ditingkatkan (Senturan, Kose, Sabuncu, \& Ozhan, 2012), juga dipengaruhi oleh latar kebudayaan mereka. Sebuah studi menunjukkan bahwa cara mahasiswa Amerika memandang kemandirian lebih tinggi dibandingkan mahasiswa Jepang (Todo, Sun, \& Inoue, 2016). Peserta didik perlu meningkatkan persepsi tentang kemandirian agar performa akademik mereka meningkat, namun pada peserta didik dengan latar budaya tertentu, mereka tidak perlu meningkatkan persepsi terhadap kemandirian agar performa akademik mereka meningkat karena persepsi kemandiran mereka telah tinggi.

\section{SIMPULAN}

Berdasarkan hasil penelitian pada peserta didik SMP Negeri I0 Yogyakarta tahun pelajaran 2016/2017 yang telah dilaksanakan, dapat disimpulkan bahwa ada hubungan positif antara persepsi terhadap layanan bimbingan belajar dengan kemandirian belajar. Semakin baik persepsi peserta didik terhadap layanan bimbingan belajar, maka tingkat kemandirian mereka juga akan tinggi. Terkait dengan temuan ini, Guru BK perlu memberikan informasi kepada peserta didik mengenai pemberian layanan bimbingan belajar di sekolah secara kontinu, agar peserta didik mampu mempertahankan kondisi belajar agar tetap baik dan meningkatkan cara belajar dengan baik, sehingga mampu mandiri dalam belajar. Sekolah, dalam hal ini perlu memiliki strategi layanan bimbingan belajar lewat pembuatan kelompok belajar di luar jam pelajaran, agar peserta didik mendapatkan layanan dengan optimal agar pihak sekolah mampu membantu peserta didik mengembangkan kemampuan belajarnya secara optimal.

\section{DAFTAR RUJUKAN}

Amin, S. M. (2010). Bimbingan dan Konseling Islam. Amzah.

Azwar, S. (2013). Penyusunan Skala Psikologi. Yogyakarta: Pustaka Pelajar.

Brouzos, A., Vassilopoulos, S., Korfiati, A., \& Baourda, V. (2015). Secondary School Students' Perceptions of Their Counselling Needs in an Era of Global Financial Crisis: An Exploratory Study in Greece. International Journal for The Advancement of Counselling, 37(2), 168-178. 
Çakiroğlu, Ü., \& Öngöz, S. (2017). The Effectiveness of Peer Tutoring in Remedying Misconceptions of Operating System Concepts: A Design-based Approach. Education and Information Technologies, 22(3), 1249-1269. https://doi.org/10.1007/s10639-016-9490-0

Creswell, J. W. (2002). Educational Research: Planning, Conducting, and Evaluating Quantitative. Prentice Hall Upper Saddle River, NJ.

Da Re, L., Clerici, R., \& Álvarez Pérez, P. R. (2017). The Formative Tutoring Programme in Preventing University Drop-outs and Improving Students' Academic Performance. The Case Study of The University of Padova (Italy). Italian Journal of Sociology of Education, 9(3), 156-175. https://doi.org/10.14658/pupj-ijse-2017-3-7

Dabone, K. T., Graham, Y. A., \& Fabea, I. B. (2015). Impact of Guidance and Counseling on Academic Performance. Research on Humanities and Social Sciences, 5(8), 225-227.

Erikson, E. H. (1994). Identity: Youth and Crisis. WW Norton \& Company.

Feist, J., \& Feist, G. J. (2002). Student Study Guide for Use with Theories of Personality. McGrawHill.

Fitriana, S., Ihsan, H., \& Annas, S. (2015). Pengaruh Efikasi Diri, Aktivitas, Kemandirian Belajar dan Kemampuan Berpikir Logis Terhadap Hasil Belajar Matematika pada Siswa Kelas VIII SMP. Journal of EST, 1(2), 86-101.

Holland, A. L., Grant, C., \& Donthamsetty, R. (2018). An Instrumental Case Study on Testing an Integrated Framework for Tutoring Sessions. Qualitative Report, 23(3), 557-580.

Kementerian Pendidikan dan Kebudayaan. (2015). Peraturan Kementerian Pendidikan dan Kebudayaan Republik Indonesia Nomor 111 Tahun 2014 tentang Bimbingan dan Konseling pada Pendidikan Dasar dan Pendidikan Menengah. Jakarta: Depdikbud.

Levesque, C., Zuehlke, A. N., Stanek, L. R., \& Ryan, R. M. (2004). Autonomy and Competence in German and American University Students: A Comparative Study Based on Self-determination Theory. Journal of Educational Psychology, 96(1), 68-84. https://doi.org/10.1037/00220663.96.1.68

Modo, F., Sanni, K., \& Mogbo, C. U. P. I. (2013). Guidance and Counseling Services in Secondary School as Coping Strategy for Improved Academic Performance of Students in Akwa Ibom State, Nigeria. Guidance and Counseling, 3(4), 43-47.

Nyutu, P. N., \& Gysbers, N. C. (2008). Assessing the Counselling Needs of High School Students in Kenya. International Journal for Educational and Vocational Guidance, 8(2), 83-94. https:// doi.org/10.1007/s10775-008-9140-1

Prasertsung, P., Chano, J., \& Boonleang Thumthong, J. (2012). Development of Guidance Activity Management for Enhancing Matayomsuksa 4 students' Self-love and Self-understanding Based on Contemplative Education. European Journal of Social Sciences, 28(1), 5-12.

Prasetya, I. G. R., Winarno, R. D., \& Eriany, P. (2013). Bimbingan Belajar Efektif untuk Meningkatkan Kebiasaan Belajar pada Siswa Kelas VII. PREDIKSI, 2(1), 1-4.

Reeve, J., \& Jang, H. (2006). What Teachers Say and Do to Support Students' Autonomy During A Learning Activity. Journal of Educational Psychology, 98(1), 209-218. https://doi. org/10.1037/0022-0663.98.1.209

Senturan, L., Kose, S., Sabuncu, N., \& Ozhan, F. (2012). Autonomy and Submissive Behaviour Among Students at The College of Nursing. HealthMED, 6(8), 2741-2748.

Sriyono, H. (2016). Program Bimbingan Belajar untuk Membantu Meningkatkan Kemandirian Belajar Siswa. Sosio e-kons, 8(2), 118-131.

Sunarsih, T. (2010). Hubungan Antara Motivasi Belajar, Kemandirian Belajar dan Bimbingan Akademik terhadap Prestasi Belajar Mahasiswa di STIKES A. Yani Yogyakarta. Universitas Sebelas Maret. 
Todo, N., Sun, Y., \& Inoue, S. (2016). Effects of Perceived Autonomy on Student Engagements and Academic Performance in Japanese University Students. In Proceedings - 2016 5th IIAI International Congress on Advanced Applied Informatics, IIAI-AAI 2016 (hal. 517-522). https://doi.org/10.1109/IIAI-AAI.2016.140

Winkel, W. S., \& Hastuti, M. M. S. (2005). Bimbingan dan Konseling di Institusi Pendidikan. Media Abadi.

Zhan, S., Bray, M., Wang, D., Lykins, C., \& Kwo, O. (2013). The Effectiveness of Private Tutoring: Students' Perceptions in Comparison with Mainstream Schooling in Hong Kong. Asia Pacific Education Review, 14(4), 495-509. https://doi.org/10.1007/s12564-013-9276-7 